\title{
El Consejo de la Hispanidad
}

\author{
Mercedes Barbeito DIEZ
}

El término «Hispanidad» tuvo en la posguerra española un sentido definido a partir de una serie de textos, el primero de los cuales es el discurso que pronunció el Jefe del Estado en Zaragoza el año 1939 con motivo de la fiesta de la Raza, donde se refería a la necesidad de proyección del régimen en Hispanoamérica '. Su formulación se fue concretando en editoriales, oficialmente inspiradas, conmemorativas de dicha festividad un año después. Así, en Arriba se afirmaba: "Nuestro hispanoamericanismo es éste: ante la aurora del mundo que nace, España ... hoy comunica el nuevo espíritu". En el mismo editorial se definía la doctrina hispanoamericanista de Falange: "Respecto a los países de América, mantenemos la unificación de cultura, de intereses económicos $y$ de poder" ${ }^{2}$. En $A B C$ se consideraba la Hispanidad como una comunidad espiritual ayudada por una comunidad de idioma ${ }^{3}$, concepción que se completaba en el editorial de Pueblo añadiendo un nuevo factor, la religión. La Hispanidad se concebía así como una comunidad de costumbres derivadas de principios religiosos. Se utilizaban las palabras de Primo de Rivera para insistir en el papel preeminente de España dentro de esa comunidad: «España se justifica por una vocación imperial para unir lenguas, para unir razas, para unir pueblos" ${ }^{4}$. Este planteamiento implicaba un papel de liderazgo espiritual y formal de España hacia la comunidad hispanoamericana, dejaba ver los deseos que existían dentro del régimen por conseguir esa unidad y la aceptación de las veinte naciones hispanoamericanas de estos planteamientos ideológicos.

\footnotetext{
2 «La Falange y el mundo hispánico», Arriba, 19 de octubre de 1940.

3 "Lo que representa la Hispanidad", $A B C, 13$ de octubre de 1940.

4 "Vocación imperial", Pueblo, 12 de octubre de 1940.
} de 1939.

" «Discurso del General Franco en Zaragoza el día de la Raza", Arriba, 13 de octubre 
Junto a estas formulaciones teóricas se iba desarrollando una ideología hispanoamericanista con un sentido más práctico, con una proyección más concreta, que buscaba unos ecos directos en la vida cultural y social de esa comunidad proponiendo para ello distintas iniciativas: creación de un Colegio Mayor de la Hispanidad, intercambio de conferenciantes y catedráticos, exposiciones, becas... ${ }^{5}$. Se insistía así en la supremacía de la cultura común como nexo de unión, relegando al olvido los aspectos económicos y de poder.

En el año 1940 funcionaban en España varias asociaciones de tipo privado, cuyo objetivo era la búsqueda de vínculos culturales comunes entre España e Hispanoamérica ${ }^{6}$. De todas ellas, las más destacada era la «Asociación Cultural Hispano Americana», que por su organización, su plan metódico de trabajo basado en una doctrina «leal al sentimiento genuino de España», su división para este trabajo en secciones y su insistencia en los aspectos culturales, se podría considerar el antecedente más cercano al Consejo de la Hispanidad. Dada su importancia se trata expresamente a continuación.

El 5 de febrero de 1940, don Enrique Varela, jefe de las Secciones de Relaciones Culturales y de Santa Sede y Obra Pía del Ministerio de Asuntos Exteriores, presentó ante el director General de Seguridad, Conde de Mayalde, los estatutos de la «Asociación Cultural HispanoAmericana». En dicho escrito se aseguraba que los fines de dicha institución eran el "fomentar las relaciones culturales entre los países que integran el mundo Hispano-Americano" ?

Esta carta estaba acompañada de un informe confidencial del ministro de Asuntos Exteriores, Beigbeder, al Conde de Mayalde, manifestando la urgencia que tenía la aprobación de dichos estatutos. En este informe se reconocía que la Asociación Cultural Hispano Americana venía a reemplazar a la antigua "Unión lbero Americana", cuyos procedimientos parece ser que no encajaban bien con los «modos y normas peculiares de nuestro Movimiento". También se notificaba que la nueva

\footnotetext{
5 "La Hispanidad de nuestro tiem,oo", discurso pronunciado por el Presidente de la Asociación Cultural Hispano Americana, 11 de octubre de 1940. AMAE, R1730/111.

${ }^{6}$ Entre otras la sociedad Hispanidad, $A M A E$, R3563/24, y la Real Sociedad Colombina Onubense, AMAE, R2461/75.

7 "Instancia dirigida al director General de Seguridad por Enrique Varela, miembro de la Junta de Patronato de la Asociación Cultural Hispano Americana", 5 de febrero de 1940, AMAE, R1382/12.
} 
institución, pese a aparecer como entidad privada, tenía un carácter oficioso, por estar "controlada por nosotros" ${ }^{8}$.

Este carácter oficioso se reafirmaba en un informe posterior en el que se trataba la posible subvención de que podría disponer la Asociación Cultural Hispano Americana por parte del Ministerio de Asuntos Exteriores. En dicho informe se reconocía la importancia de la presión del ministro de Asuntos Exteriores para constituir la Asociación, lo que le permitiría disponer de un instrumento adecuado para el desarrollo de la política y la expansión cultural en Hispanoamérica ${ }^{9}$.

Los estatutos de la Asociación Cultural Hispano Americana se aprobaron en marzo de 1940 y constaban de nueve artículos y una disposición transitoria. Los dos primeros artículos eran, en realidad, una declaración de intenciones, donde se recogían la finalidad de la Asociación, -el estrechar los vínculos culturales que ligaban a España y América-, y deseo de la citada Asociación de constituir entidades análogas por toda Hispanoamérica ${ }^{10}$.

La Asociación Cultural Hispano Americana se constituyó para su funcionamiento con la Junta de Patronato, compuesta por diecisiete personas, cuya relación aparecía en los propios estatutos, de la que se escogían un Presidente y un Vicepresidente. Éstos estaban auxiliados en sus funciones por un Secretario General y por tres Comisiones (Cultura; Propaganda, Fiestas y Recreos; Administración y Contabilidad). Para cubrir todas las áreas de trabajo, se establecían diferentes Secciones, hasta un total de diecisiete, de las que se podría destacar (dado su paralelismo con la organización futura del Consejo de la Hispanidad) la Sección Religiosa, que gozaba de una considerable importancia, de acuerdo con la mentalidad de la época ". En un escrito titulado Origen y Fines de la Asociación Cultural Hispano Americana, se hacía hincapié en la significación del dogma católico dentro de dicha Asociación, y se recordaba que, precisamente, existía esa Sección Religiosa de trabajo para garantizar la ortodoxia en el desenvolvimiento cultural de la Asociación. La Asociación Cultural Hispano Americana tenía una misión ordenada hacia

\footnotetext{
8 "Carta del ministro de Asuntos Exteriores al director General de Seguridad», 3 de febrero de 1940, AMAE, R1382/12.

9 "Informe sobre la subvención a la Asociación Cultural Hispano Americana por el Ministerio de Asuntos Exteriores", 8 de abril de 1940, AMAE, R1382/12.

${ }^{10}$ «Estatutos de la Asociación Cultural Hispano Americana, AMAE, R1382/12.

11 "Constitución de la Asociación Cultural Hispano Americana", AMAE, R1382/12.
} 
Dios: llevar a Dios a todos los hombres del mundo hispánico, a través de la cultura hispánica. Incluso se llegó a sugerir un lema del tipo «a Dios por el fomento de la cultura hispánica» ${ }^{12}$.

La importancia del apoyo de la religión en el funcionamiento de la Asociación Cultural Hispano Americana quedó patente con la visita de su Presidente al Papa y a los Jefes de las Órdenes Religiosas, pidiendo la aprobación y bendición de la empresa que se perseguía. En todas las visitas mencionadas se les presentó un artículo titulado "Catolicismo e Hispanidad», donde se manifestaba que la Asociación serviría al pensamiento de unidad y de fe y se reconocía que la Hispanidad nacía «del sentido católico proyectado como norma de vida individual y colectiva" ${ }^{13}$.

Sin embargo, esta faceta espiritual encubría una realidad mucho más práctica. Se trataba de hacer comprender y compartir a Hispanoamérica la ideología que llevó al 18 de julio del 36 . Por ello se insistía en que el Movimiento Nacional era "la respuesta de los últimos gérmenes de hispanidad que quedaban en España" y en la necesidad de hacer comprender a las juventudes de América la justificación de la Cruzada ${ }^{14}$.

Para facilitar la difusión de esa nueva ideología, la Asociación Cultural Hispano Americana se imponía un plan de trabajo basado en los siguientes puntos: creación de un Colegio Mayor de la Hispanidad, intercambio de conferenciantes, de profesores, becas para estudiantes, Congresos, publicación de una revista, formación de una biblioteca y una hemeroteca especializadas en temas hispanoamericanos, $y$, finalmente, la propaganda, a fin de realizar una penetración eficaz en el mundo hispánico ${ }^{15}$. No deja de ser significativo que la subvención que le concedió el Ministerio de Asuntos Exteriores, citadá anteriormente, se libró del crédito de Material de Propaganda e Imprevistos.

Los objetivos de la Asociación con respecto a Hispanoamérica se concretaban en dos tipos de gestiones. De una parte había que realizar una función informativa que cubriese aspectos culturales, sociedades y personalidades, y de otra, se llevaría a cabo una función propagandística

12 «Origen y fines de la Asociación Cultural Hispano Americana», AMAE, R1382/12.

13 «Catolicismo e Hispanidad», AMAE, R1382/12.

14 "Necesidad y justificación de la Asociación Cultural Hispano Americana», AMAE, $\mathrm{R} 1382 / 12$.

15 «Fines de la Asociación Cultural Hispano Americana», AMAE, R1382/12. 
de la Asociación, con distribución de las publicaciones propias y adhesiones de figuras de relieve, que la prestigiasen ${ }^{16}$.

Ese carácter oficioso, y, por tanto, con una subordinación a las ideas del régimen, pondrá en graves aprietos la perduración de la Asociación Cultural Hispano Americana. El caso más conocido fue el del Dr. Francisco Umana Bernal, embajador de Colombia en España y decano del Cuerpo Diplomático Hispanoamericano, nombrado por Estatutos miembro de la Junta de Patronato de la Asociación Cultural Hispano Americana. En una reunión a la cual este embajador no pudo asistir, la Junta aprobó por unanimidad un escrito titulado Puntos de vista sobre Hispanoamérica. En dicho escrito se atacaban, entre otras materias, la mentalidad y la ideología liberal, el panamericanismo al ser la negación y réplica del hispanoamericanismo, la revolución industrial llevada por manos extranjeras, etcétera... ${ }^{17}$. Ante estas taxativas afirmaciones el Sr. Umana presentó su dimisión, alegando, como embajador de Colombia, que no podía «acoger, compartir ni aceptar" tales ideas, ya que en Colombia el liberalismo era una de las fuerzas políticas más respetables del país, "a la que pertenece el actual gobierno", y la política panamericana era una de las bases de la política internacional de Colombia. Pero, además, había un rechazo total al resto del escrito ${ }^{18}$.

Esta ideología del hispanoamericanismo en lucha contra liberalismo y panamericanismo, muy extendidos en Hispanoamérica, traería graves problemas a la política de Hispanidad propugnada por el régimen.

El Consejo de la Hispanidad, que se creó por Ley de la Jefatura del Estado de 2 de noviembre de 1940, tenía como misión llevar adelante el ideal de Hispanidad. España, como «eje espiritual del mundo hispánico», era el país al que correspondía el dirigir este organismo, y dar un nuevo aire a la política hispanoamericana. Además, gracias a las funciones del Consejo, España sería la representación de Europa ante Hispanoamérica, función en la que los dirigentes del Consejo de la Hispanidad insistirían a menudo: «España es una nación más del continente americano, y por la presencia geográfica de esta España europea, las naciones de Amé-

16 «Para Hispano-América», AMAE, R1382/13.

17 «Puntos de vista sobre Hispano-América», 9 de junio de 1940. AMAE, R1382/13.

18 "Carta del Sr. Umana al Sr. García Mansilla", 10 de junio de 1940. AMAE, R1382/ 12. 
rica no tendrán por qué renunciar a Europa» ${ }^{19}$. Se insistía en que esta era una tarea con un componente exclusivamente espiritual, ya que España no intentaba con ella conquistas de tierras o riquezas, sino sólo estar presente en América y devolver a la Hispanidad una conciencia de comunidad. Sin embargo, esta afirmación del preámbulo entraba en clara contradicción con lo expuesto en uno de los artículos, donde se le asignaban al consejo todas las actividades que tendieran a la unificación no sólo de la cultura, sino de los intereses económicos y de poder relacionados con el mundo hispano.

El articulado, muy breve, establecía que el Consejo de la Hispanidad era un organismo asesor, dependiente del Ministerio de Asuntos Exteriores, que velaría por los intereses de España en el mundo hispánico y dirigiría toda la política relacionada con Hispanoamérica. Dejaba en manos del ministro de Asuntos Exteriores el nombramiento de Consejeros y el dictado de normas para la constitución del Consejo, asi como para tomar cualquier decisión relacionada con las asociaciones que en ese momento estaban funcionando con objetivos similares ${ }^{20}$.

Dos meses después, una orden ministerial desarrollaba la institución, pretendiendo que el Consejo agrupara a las personalidades más destacadas del mundo hispánico. España no estaba inmune al afán propagandístico y sensacionalista de los regímenes dictatoriales de la época, y aspiraba a que el Consejo de la Hispanidad fuera aceptado por las veinte naciones hispanoamericanas, convirtiéndose en un organismo supranacional, una especie de parlamento hispanoamericano, que anunciara al mundo entero el poder de esta comunidad. Pero, por el momento, y ante la imposibilidad de que se cumpliesen estos sueños, se organizaba la constitución del Consejo en términos más "caseros". Entraban a formar parte de él una serie de personalidades destacadas del régimen, unas en razón de su cargo y otras a título personal. Entre los primeros era cuantiosa la representación del Ministerio de Asuntos Exteriores, empezando por el propio ministro, nombrado Presidente del Consejo de la Hispanidad (en razón del cargo). Estaban representados también miembros de otros Ministerios, así como de FET y de las JONS. El segundo

${ }^{19}$ «Alocución dirigida por radio a los pueblos de la América española por el Canciller del Consejo de la Hispanidad, Manuel Halcón, con motivo del IV centenario de la muerte de Pizarro", 26 de junio de 1940. AMAE, R1080/25.

${ }_{20}$ Ley de 2 de noviembre de 1940. 
grupo lo constituían 53 personas, que se podrían clasificar en varias categorias: intelectuales, militares, falangistas, eclesiásticos...

El número de Consejeros no quedaba cubierto con estos nombramientos, pues no era limitado, y el Ministro tenía autorización para nombrar Consejero a cualquier persona que destacara en la vida española en relación con la Hispanidad. En la misma orden que establecía la constitución del Consejo de la Hispanidad se disponía que éste tuviera su residencia en Madrid, pero, cuando empezara a funcionar la rama hispanoamericana, se designaría una ciudad americana para su residencia ${ }^{21}$.

En abril de 1941 se aprobó el primer Reglamento que había de regir el funcionamiento del Consejo de la Hispanidad ${ }^{22}$, que se establecía como organismo interministerial y se hacía cargo de todas las actividades relacionadas con Hispanoamérica, con el fin de establecer una sola actuación, evitando la dispersión en distintos Ministerios y entidades oficiales. El Presidente del Consejo de la Hispanidad, cargo que iba ligado al de ministro de Asuntos Exteriores, asumía la representación legal del Consejo y tenía la facultad de designar a los nuevos Consejeros ${ }^{23}$.

En lo que se refería a organización interna, y para dar mayor capacidad de funcionamiento al Consejo, se distinguía el «Consejo en pleno», órgano general de gobierno, con funciones fundamentalmente asesoras, de la "Cancillería", a la que correspondía la orientación, coordinación y ejecución de los trabajos del Consejo. La Cancillería estaba formada por el Canciller, el Secretario y los consejeros Asesores. El cargo de Canciller recaía en la persona que ostentaba la Dirección General de América en el Ministerio de Asuntos Exteriores. Sus funciones comprendían desde representar al Presidente y funcionar como órgano transmisor entre éste y el Secretario, hasta decidir la ordenación del trabajo o proponer personal. En este primer Reglamento el jefe efectivo de la organización administrativa era el Secretario de la Cancillería. Este cargo era cubierto por una persona elegida por el Presidente entre los miembros del Consejo ${ }^{24}$.

\footnotetext{
${ }^{21}$ Orden de 7 de enero de 1941.

22 Orden de 7 de abril de 1941.

23 "Lista de designación de nuevos Consejeros del Consejo de la Hispanidad», 12 de octubre de 1941. AMAE, R1080/25.

${ }^{24}$ De la obligatoriedad de esta condición nos habla, además del Reglamento, la nota sobre la propuesta de nombramiento de Consejo de la Hispanidad a favor de Tomás Súñer Ferrer, escrita por el Canciller del Consejo de la Hispanidad al Presidente del mismo, con fecha 19 de febrero de 1943. Tomás Súñer y Ferrer había sido nombrado Secretario del Consejo de la Hispanidad el 8 de febrero de ese año. AMAE, R2461/75.
} 
El nombramiento directo por el Presidente pudo dar lugar a «puenteos» en las actuaciones del Canciller, situación que se solventó con la publicación de un nuevo Reglamento, el 12 de diciembre de 1941, que daba mayor protagonismo a la figura del Canciller ${ }^{25}$.

La Cancillería, con el fin de hacer frente a todas las actividades que le competian, se devidía en cinco secciones: Cultural, Política, Económica, Social y Jurídica, cada una de las cuales tenía a su cargo distintas actuaciones, aunque en la práctica era muy difícil su separación. Estaban dirigidas por un Jefe de Sección nombrado por el Presidente del Consejo a propuesta del Canciller.

La representación del Consejo de la Hispanidad en América la ostentaban los embajadores de España en Argentina, Cuba, Chile, México (sic) y Perú. Los demás representantes españoles en América y Filipinas debian relacionarse directamente con el Consejo de la Hispanidad. Sin embargo, esta cooperación, pese a las órdenes del Ministro de Asuntos Exteriores a tal efecto ${ }^{26}$, fue más deseada que real, viéndose afectada por dificultades y retrasos en las comunicaciones de hasta cuatro meses, lo que provocó las quejas del Canciller ${ }^{27}$.

El Consejo dependía económicamente de un presupuesto oficial que se le asignaba por el Ministerio de Asuntos Exteriores. Además se hacía cargo de donaciones y legados de entidades particulares, que se podian destinar tanto al Consejo como a fines más específicos, entre los que se incluian la creación de cátedras, dotación de becas, etc.

La importancia que dentro del Consejo de la Hispanidad se daba a la parafernalia típica de la época quedaba de manifiesto en las disposiciones sobre el uso de insignias que debían utilizar los miembros del Conšejo, con el emblema del mismo, así como que «la medalla del Presidente será de tamaño visiblemente mayor que la del Canciller».

${ }^{25}$ Orden de 12 de diciembre de 1941.

26 «Telegrama del ministro de Asuntos Exteriores a todas las representaciones españolas en América y al Cónsul General en Manila», 10 de septiembre de 1941. AMAE, R1652/62.

${ }_{27}$ «Nota del Canciller del Consejo de la Hispanidad al subsecretario de Asuntos Exteriores, quejándose del retraso en las comunicaciones postales", 12 de enero de 1942. AMAE, R1652/62. 
El Consejo de la Hispanidad empezó a funcionar con la publicación de su primer Reglamento, pero su período vital fue, salvo una primera etapa, que coincidiría con la presencia de Ramón Serrano Súñer como Ministro de Asuntos Exteriores, de un constante decaimiento. El nombramiento para el cargo de Gómez Jordana y su nueva orientación de neutralidad en política exterior se tradujeron en un abandono paulatino del Consejo de la Hispanidad. No parece demasiado arriesgado, pues, relacionar la creación de este organismo con una determinada orientación de la política exterior franquista, en este caso con la germanofilia defendida por Serrano Súñer. Ello daría la razón a los que veían en el Consejo de la Hispanidad más un intrumento de la política exterior alemana que un reflejo de una política hispanista por parte del régimen de Franco.

El primer acto público que organizó el Consejo de la Hispanidad fue con motivo del IV Centenario de la muerte de Pizarro. Manuel Halcón, Canciller del Consejo, hizo un discurso de intenciones en el que afirmaba que el Consejo nacía para salvar la cultura hispánica, común denominador de los pueblos hispanoamericanos, pero recalcaba que no se pretendían hegemonías ni posiciones de privilegio. Igualmente desmentía posibles influencias ajenas a España en la fundación del mismo, e insistía en la vocación de España de servir de nexo entre Europa y las naciones de América ${ }^{28}$.

En la prensa peruana el acto fue, en general, mal recibido, insistiendo en que la política hispanista del Gobierno español respondía a su compromiso de secundar una política conforme a las ambiciones hitlerianas ${ }^{29}$, y que celebrar "los arrestos del conquistador" era despreciar la obra de los que rescataron la tierra americana, devolviendo a esos pueblos la libertad ${ }^{30}$. No se conocen las influencias que pudieron tener estas críticas, pero el hecho cierto es que, a partir de este momento, las celebraciones de que se tiene constancia son de carácter mucho más general, exaltación de causas comunes, como es el caso del día de la Hispanidad o la conmemoración de gestas colombinas.

El 12 de octubre de 1941 se celebraron en Madrid los actos de la fiesta de la Hispanidad, por primera vez patrocinados por el Consejo de

${ }^{28}$ Ver nota (19).

29 «El falangismo en danza», Crónica, Perú, 7 de julio de 1941. AMAE, R1652/68.

30 "El signo de la conquista abolido de América», Crónica, Perú, 30 de junio de 1941. AMAE, R1652/68. 
la Hispanidad. La sesión se inauguró con un acto en el Senado, presidido por el Jefe del Estado, que en su discurso animó al Consejo a continuar la tarea emprendida. A continuación se sirvió una comida de gala ofrecida al Cuerpo Diplomático iberoamericano, y por la noche se organizó una función en el Teatro Español a la que asistieron el Cuerpo Diplomático y el Gobierno en pleno ${ }^{31}$.

La siguiente celebración de la fiesta de la Hispanidad se realizó siendo ya ministro de Asuntos Exteriores Gómez Jordana. El giro en política exterior del régimen quedaba patente en las consignas que se dieron a la prensa: «evitar toda referencia a la guerra actual, evitar la palabra Imperio, evitar todo lo que pueda interpretarse en el sentido de que España desearía ocupar una posición tutelar respecto a los países de nuestro idioma" ${ }^{32}$. El principal acto del día fue la emisión radiofónica de los discursos pronunciados por los ministros de Exteriores de España, conde de Jordana, y Argentina, Ruiz Guiñazú. Ambas naciones vivian un período de acercamiento, que se traducía en el apoyo manifestado a través del discurso del ministro argentino ${ }^{33}$, muy bien recibido en los medios oficiales españoles ${ }^{34}$. En su contestación, el Conde de Jordana afirmaba el orgullo que suponía para España el ver a las naciones que se separaron de su imperio jugando un importante papel en el mundo, y hacía un llamamiento a sus juventudes «en las cuales ha de basarse la grandeza futura y el destino común de sus países» ${ }^{35}$. Ambos discursos fueron recogidos con alabanzas por la prensa española ${ }^{36}$.

\footnotetext{
31 «Resumen de actos celebrados con ocasión del 12 de octubre de 1941», AMAE, R1081/17.

${ }_{32}$ "Consignas para el día de la Raza a la prensa y entidades oficiales de toda España", Ministerio de Asuntos Exteriores. AMAE, R1080/25.

${ }^{33}$ «Telegrama de la Embajada de España en Argentina al ministro de Asuntos Exteriores, côn la síntesis del discurso del ministro de Relaciones Exteriores de Argentina, Dr. Ruiz Guiñazú", 10 de octubre de 1942. AMAE, R1081/17.

${ }^{34}$ «Telegrama enviado por el ministro de Asuntos Exteriores de España al ministro de Relaciones Exteriores de Argentina", 13 de octubre de 1942. AMAE, R1081/17.

35 «Borrador del discurso del ministro de Asuntos Exteriores con ocasión de la fiesta de la Hispanidad de 1942", AMAE, R1080/25.

${ }^{36}$ Las palabras de Ruiz Guiñazú están fundadas en el más sólido criterio e inspiradas en una realidad honda y trascendente. "La Hispanidad ante el mundo", YA, 13 de octubre de 1942; El Dr. Ruiz Guiñazú ha ofrecido a España el máximo homenaje de reconocimiento por la obra incomparable de nuestra patria en América. "La verdad de España», Arriba, 13 de octubre de 1942; El Dr. Ruiz Guiñazú proclama con sus palabras los cordiales sentimientos de la nación argentina hacia la española. "De uno al otro lado del Atlántico", $A B C$, 13 de octubre de 1942.
} 
Aparte de la Argentina, en los demás países hispanoamericanos se celebró la festividad de formas bien diferentes. Así, mientras en Chile se organizaron varios actos con asistencia del Cuerpo Diplomático y miembros del Gobierno ${ }^{37}$, en Perú hubo una total abstención por parte de Gobierno y sectores oficiales ${ }^{38}$.

El año 1943 el Consejo de la Hispanidad planteó realizar un homenaje a todas las naciones de Hispanoamérica, que se cerraría el 15 de abril en Barcelona, con la conmemoración de la vuelta de Colón ${ }^{39}$. En el programa se incluían exposiciones de libros, actos culturales y una reunión del Consejo. Este programa fue remitido a la Sección de Relaciones Culturales del Ministerio de Asuntos Exteriores a petición del ministro, para que se informara ${ }^{40}$, lo que parecía indicar que el Consejo no gozaba ya de la autonomía que poseía anteriormente. En el informe de dicha Sección se insistía en la conveniencia de que la intervención del Consejo debía limitarse a los actos netamente culturales, y se consideraba más prudente que la reunión del Consejo se celebrase en Madrid, asistiendo a los actos sólo una representación del mismo ${ }^{41}$. Este último punto del informe fue el único en que el ministro no estuvo de acuerdo, dado «que el propio ministro se propone presidir» dicha sesión ${ }^{42}$.

Con la llegada de la fecha de celebración, el Consejo de la Hispanidad perdía aún más protagonismo. Por orden del ministro, se suprimía la intervención prevista del Canciller ${ }^{43}$. A continuación, en una nota urgente de la Secretaría del ministro de Asuntos Exteriores a la prensa se insistía en que la organización de los actos de Barcelona se había hecho enteramente por el Ministerio, y se daban consignas para evitar el citar continuamente a Consejeros de la Hispanidad y no hacerlo con el Conde de

\footnotetext{
${ }^{37}$ «Telegrama de la Embajada de España en Chile al ministro de Asuntos Exteriores», AMAE, R1080/25.

${ }^{38}$ "Telegrama de la Embajada de España en Perú al ministro de Asuntos Exteriores», AMAE, R1080/25.

${ }^{39}$ "Programa de actos a celebrar en Barcelona el 15 de abril, organizados por el Consejo de la Hispanidad", AMAE, R2461/75.

${ }_{40}$ "Nota de la Secretaría particular del ministro a la Sección de Relaciones Culturales", Ministerio de Asuntos Exteriores, 8 de enero de 1943. AMAE, R2461/75.

41 "Nota de la Sección de Relaciones Culturales al Ministro", Ministerio de Asuntos Exteriores, 30 de enero de 1943. AMAE, R2461/75.

${ }_{42}$ Anotación a mano sobre la nota anterior, AMAE, R2461/75.

43 "Nota dirigida por el ministro de Asuntos Exteriores a los Sres. Súñer y Casares", 8 de marzo de 1943. AMAE, R1080/10.
} 
Jordana ${ }^{44}$. Asimismo, se prohibía en los discursos relacionados con el acto cualquier referencia a la política internacional "cuestión que es de la única competencia del ministro de Asuntos Exteriores" ${ }^{45}$.

El ministro utilizó el foro del Consejo de la Hispanidad para exponer el giro de la política exterior franquista. Despachó toda referencia a la conmemoración con unos comentarios a los discursos pronunciados anteriormente por los embajadores de Chile y Argentina, para tratar a continuación el tema que le interesaba: las nuevas propuestas españolas para la resolución del conflicto mundial. A España le incumbía una gran misión: «facilitar el restablecimiento de la paz sobre la tierra» ${ }^{46}$.

En los periódicos españoles de ese día y de días sucesivos la atención principal se centraba en dicho discurso. Los únicos periódicos que dedicaban algún comentario al acto en sí y a ensalzar la idea de Hispanidad eran Pueblo, donde se escribía: "La proyección de la Hispanidad ante el mundo en armas se agiganta» ${ }^{47}$, y El Alcazar, que afirmaba: «En la sesión solemne celebrada ayer por el Consejo de la Hispanidad se pronunciaron discursos en los que volvieron a glorificarse los gestos no igualados de la Madre Patria" ${ }^{48}$.

Los telegramas recibidos desde las representaciones diplomáticas recogían el gran eco que el discurso había tenido en los distintos países, pero la opinión generalizada era que formaba parte de una campaña de opinión del Eje, con vistas a lograr una paz negociada ${ }^{49}$. Ante dichas interpretaciones el ministro de Asuntos Exteriores enviaba a todas las representaciones españolas en Hispanoamérica una circular afirmando el rechazo que la iniciativa española había tenido por las potencias del Eje, así como «la coincidencia de los puntos de vista españoles con los del

44 "Nota urgente firmada por el secretario del ministro", Ministerio de Asuntos Exteriores. 14 de abril de 1943. AMAE, R1080/10.

45 «Nota de la Dirección General de Política Exterior», Ministerio de Asuntos Exteriores, 9 de abril de 1943. AMAE, R1080/10.

${ }^{46}$ "Folleto editado con los discursos pronunciados en la sesión del Consejo de la Hispanidad celebrada en Barcelona con mctivo del 450 aniversario del regreso de Colón», abril de 1943. AMAE, R1732/10.

47 "La paz sobre la tierra", Pueblo, 17 de abril de 1943.

48 «España es la paz", El Alcázar, 17 de abril de 1943.

49 "Telegramas recibidos en el Ministerio de Asuntos Exteriores enviados desde las representaciones españolas, informando de la repercusión del discurso del ministro", abril de 1943. AMAE, R1372/10. 
último discurso de Churchill", como muestra de la independencia de la postura internacional de España ${ }^{50}$.

En julio de 1943, Manuel Halcón cesó en el cargo de Canciller, tras firmar el llamado «manifiesto monárquico» ${ }^{51}$. Le sustituía en sus funciones, que no en su cargo, el recientemente nombrado Secretario del Consejo, Tomás Súñer y Ferrer ${ }^{52}$. La documentación demuestra que había intenciones de cubrir el puesto en diciembre de $1943^{53}$, pero nunca llegaron a concretarse y así, el Consejo de la Hispanidad se mantendría, desde dos años antes de su transformación en Instituto de Cultura Hispánica, en una situación de transitoriedad.

En octubre del mismo año 43 se celebraba en Madrid la fiesta de la Hispanidad. Como en la ocasión anterior, la "delicada situación internacional hacía que, previamente a la celebración, se repartieran las consignas a las publicaciones, que insistían en la necesidad de abstenerse de hacer comentarios políticos, «debiendo limitarse a tocar temas de carácter histórico, cultural, etc., relacionados con la Hispanidad» ${ }^{54}$. Los actos programados consistían en la inauguración de la Ciudad Universitaria, y una recepción en el Ministerio de Asuntos Exteriores. En el primer acto, la prensa no daba cuenta de la participación del Consejo de la Hispanidad ${ }^{55}$, mientras que en el segundo, éste mantenía cierto protagonismo, pues había sido el encargado de gestionar y pagar las ediciones facsímil de la Recopilación de las Leyes de los Reynos de las Indias, que se entregaron como obsequio a los representantes diplomáticos de Hispanoamérica y Portugal ${ }^{56}$. En el mismo Ministerio, a continuación, se celebró el acto de la firma fundacional del Museo de América, considerado de «enorme trascedencia en el mundo hispánico» ${ }^{57}$. Asimismo, y como Presidente del Consejo de la Hispanidad, el ministro de Asuntos

${ }^{50}$ «Circular enviada por el ministro de Asuntos Exteriores a las representaciones españolas en Hispanoamérica», 25 de mayo de 1943. AMAE, R1080/10.

${ }^{51}$ Comunicación privada de Manuel Halcón, 18 de junio de 1988.

52 "Nóminas del Consejo de la Hispanidad del año 1943", AMAE, R4055/3.

53 «Facturas del Consejo de la Hispanidad del año 1944». Se encarga a la casa Cejalvo, especialista en condecoraciones, un collar de Canciller del Consejo de la Hispanidad, por el importe de 6.415 pesetas. AMAE, R4052/5.

${ }^{54}$ «Carta del ministro de Asuntos Exteriores al ministro Secretario General de FET y de la JONS", 9 de octubre de 1943. AMAE, R1080/17.

${ }_{55} A B C, 13$ de octubre de 1943; Arriba, 13 de octubre de 1943.

56 «Facturas del Consejo de la Hispanidad del año 1943», AMAE, R4052/5.

${ }^{57} A B C, 12$ de octubre de 1943. 
Exteriores firmaba, con fecha 12 de octubre de 1943, las órdenes para la reparación de la casa natal de Isabel la Católica ${ }^{58}$.

El año 1944 supone un vacío en documentación. En todos los expedientes que se han trabajado relacionados con el Consejo de la Hispanidad, no aparece ningún documento que se refiera a dicho período. Por ello se ha recurrido a la prensa para conocer cómo se celebró ese año la fiesta de la Hispanidad y si el Consejo de la Hispanidad tuvo algún protagonismo.

En agosto de 1944 moría del Conde de Jordana, titular del Ministerio de Asuntos Exteriores. Para sustituirle era designado José Félix de Lequerica, bajo cuya dirección se celebró ese año la fiesta de la Hispanidad. La programación consistió en diversos actos: entrega a los jefes de misión de los países hispanoamericanos, Portugal, Brasil y Estados Unidos, de dos ejemplares, reproducción de incunables; inauguración de una exposición dedicada a la obra de Martín Navarrete; cena en el palacio de Viana en honor de las misiones diplomáticas anteriormente citadas ${ }^{59}$. El día 12 de octubre aparecían en la prensa española editoriales y artículos de fondo sobre el tema de la Hispanidad ${ }^{60}$, y el día 13 se recogía el discurso pronunciado por el ministro, cuya novedad fundamental era la inclusión de referencias a los Estados Unidos: «Pueblo de colosal proporción física y espiritual que hoy marcha a la cabeza de la civilización" ${ }^{61}$. Resultaba evidente el alejamiento de las posturas postuladas en la época de creación del Consejo. Se insistía en el afianzamiento de la neutralidad española y en el acercamiento de las potencias aliadas. Había pasado el tiempo de intentar enfrentar a las naciones hispanoamericanas con la hermana del norte, de oponer hispanoamericanismo y panamericanismo. Es posible que esa fuera la causa del languidecer del Consejo.

Hay que señalar que en la prensa consultada no aparecía ninguna referencia al papel que el Consejo de la Hispanidad había jugado en estos actos. Solamente se le mencionaba en un artículo del día posterior, y de pasada, alabando su contribución a la idea de la Hispanidad «que en silenciosa, cotidiana labor, ha editado textos insignes de espiritualidad

\footnotetext{
58 «Nota enviada a prensa el 12 de octubre de 1943», AMAE, R1081/17.

${ }^{59} A B C, 11$ de octubre de 1944.

${ }^{6} A B C, 12$ de octubre de 1944; Arriba, 12 de octubre de 1944.

${ }^{61} A B C, 13$ de octubre de 1944.
} 
admirable» ${ }^{62}$. En ningún momento se hacía referencia a la tarea política mantenida por este organismo durante los primeros años de su existencia.

El año 1945, la situación internacional exigía una readaptación en la política interna. El fin de la guerra mundial trajo consigo la condena del régimen español. Ese año los actos de celebración de la fiesta de la Hispanidad se redujeron. Aparte de la inauguración de tres edificios en la Ciudad Universitaria, sólo hubo un acto dirigido a Hispanoamérica: la emisión por Radio Nacional de un discurso del ministro de Asuntos Exteriores. En él se insistía en el acercamiento a Estados Unidos que ya se había iniciado el año anterior, se reflejaba la presión internacional que se estaba ejerciendo sobre España y se solicitaba de las naciones hispanoamericanas el no inmiscuirse en la política interna de cada Estado, "consigna sagrada para que el sentido de la hispanidad no sufra lo más mínimo por las diferencias políticas circunstanciales que pueda haber entre los pueblos de nuestra comunidad" ${ }^{63}$.

Por lo que se refiere al Consejo de la Hispanidad, aunque no aparecía para nada en la organización de estos actos, se ha encontrado documentación sobre la realización de un viaje programado por este organismo para el Cuerpo Diplomático hispanoamericano a Guadalupe, Lagartera y Oropesa, a finales del mes del octubre, «como continuación de los actos de 12 de octubre" ${ }^{64}$. Precisamente éste ha sido el último expediente que aparece relacionado con la participación en distintas conmemoraciones del Consejo de la Hispanidad, antes de su transformación en Instituto de Cultura Hispánica.

El Consejo de la Hispanidad tenía también la misión de dirigir las actividades propagandísticas del régimen, orientadas a la comunidad hispanoamericana. Esta tarea estaba encomendada, según el Reglamento, a la Sección Cultural, y duró el tiempo que se mantuvieron los planteamientos políticos que llevaron a la creación del Consejo, para luego, con la política de neutralidad de Jornada, ser abandonada. Inicialmente, la defensa y difusión de las ideas del régimen era función de los diplomáticos. En una carta enviada por un funcionario de la Embajada de España

\footnotetext{
62 «Artículo de Eugenio Montes", Arriba, 15 de octubre de 1944.

${ }^{63}$ "Discusión del ministro de Asuntos Exteriores con motivo de la celebración de la Hispanidad", $A B C, 13$ de octubre de 1945.

${ }_{64}^{64}$ "Documentación referente a dicho viaje", AMAE, R2086/14.
} 
en Venezuela se solicitaba que dichos diplomáticos fueran personas «preparadas en el nuevo credo de Falange», y se sugería el manejo de la propaganda por medios distintos de los empleados habitualmente, considerando que una actividad de tipo intelectual creaba «más vínculos que toda la campaña realizada desde la península, por más intensa que ella sea" ${ }^{65}$. Esta idea de encubrir la propaganda política con la actividad cultural se repetía en la carta que dirigía al ministro de Asuntos Exteriores el Jefe Provincial de Prensa y Propaganda, Ortega Matilla, que insistía en que una colaboración de tipo intelectual, "sin un origen oficial estrictamente, sería admirablemente recibida por todos los periódicos y revistas de habla española» ${ }^{66}$.

El uso de la radio, uno de los medios fundamentales de la época, creaba también importantes expectativas en la propaganda del régimen. La confección de los programas dirigidos a América estaba encargada al Consejo de la Hispanidad, y sus principales contenidos eran de tipo cultural ${ }^{67}$.

Bajo esta actividad intelectual el Consejo iba a centrar su propaganda en la confrontación hispanoamericanismo/panamericanismo. Se intentó aprovechar la alianza de los Estados Unidos y Rusia para justificar la posición española actuando a dos niveles. El Ministerio de Asuntos Exteriores hizo una discurso por radio, dirigido a la opinión pública, y mandó una nota por vía diplomática, donde se daba cuenta oficialmente «a los Gobiernos de América de la posición de España frente al comunismo" "68. Dentro de ese mismo enfrentamiento ideológico su situó una de las operaciones más ambiciosas impulsadas por el Consejo: el intento de aislamiento de los Estados Unidos dentro de los países americanos, lo que se conoció como ruptura del «frente único americano». La base en la que se apoyó el Consejo para esta operación fue la postura oficiosa del Brasil, supuestamente dispuesto a identificarse con Portugal en caso de que éste fuera atacado por los Estados Unidos. Para concretar las actuaciones a seguir, el mes de julio de 1941 se desarrolló una intensa

\footnotetext{
65 «Carta de Santos Valdés al ministro de Asuntos Exteriores, 7 de mayo de 1941. AMAE, R1080/25.

${ }^{66}$ "Carta de Teófilo Ortega al Ministro de Asuntos Exteriores", 10 de noviembre de 1941, AMAE, R1080/25.

${ }^{67}$ «Despacho del representante español en Uruguay al ministro de Asuntos Exteriores", 15 de abril de 1942. AMAE, R2461/107.

${ }_{68}$ «Carta del Canciller del Consejo de la Hispanidad al Presidente del mismo, ministro de Asuntos Exteriores, 8 de julio de 1941. AMAE, R1080/25.
} 
actividad diplomática, tanto por parte del Consejo como por el Ministerio de Asuntos Exteriores, cuyo objetivo era la elaboración de unas instrucciones destinadas a los embajadores españoles en Lisboa y Río de Janeiro ${ }^{69}$. Al embajador en Lisboa se le recomendaba reflejar la preocupación española por los propósitos americanos de situar bases en las islas de Cabo Verde y Azores, animando al Gobierno portugués a sacar partido de su especial relación con Brasil e intentar conseguir una declaración explícita de apoyo en caso de que se produjera dicha intervención ${ }^{70}$. Al embajador en Río se le instruía sobre una actuación en cuatro fases. En la primera debía procurar la exteriorización de la preocupación por una posible intervención americana en las islas portuguesas. La segunda fase debía desarrollarse mediante entrevista con el Ministro de Asuntos Exteriores brasileño, a quien el embajador español debía filtrar una serie ordenada de informaciones reservadas sobre posturas de Stalin y Washington en torno a estos proyectos. La tercera fase implicaba una acción conjunta con el Embajador portugués en Río, en busca de una declaración gubernamental de apoyo a Portugal en caso de crisis. Por último, y obtenida tal declaración, se trataría de incrementar al máximo su difusión, fundamentalmente entre los países hispanoamericanos ${ }^{71}$. Esta postura traería, según el Consejo, varias consecuencias: romper el frente único continental que pretendían los Estados Unidos; dar ejemplo a los pueblos de la Hispanidad sobre «la fidelidad a su origen y lazos europeos"; sembrar entre estos países el temor a una guerra en el mismo continente; $y$, por último, moderar el intervencionismo de Roosevelt en el resto de los países americanos ${ }^{72}$. Este único intento de ruptura del frente continental quedaba abortado ante la información reservada del embajador de España en Brasil, que confirmaba el alejamiento gubernamental de las posturas oficiosas en las que el Consejo había basado su estrategia ${ }^{73}$.

El fracaso en la ruptura del frente único americano no fue, sin embargo, definitivo, aunque su consecución tuviera poco que ver con las

69 «Nota del Canciller del Consejo de la Hispanidad al subsecretario de Asuntos Exteriores", 31 de julio de 1941. AMAE, R1080/25.

70 "Instrucciones al embajador en Lisboa", Ministerio de Asuntos Exteriores, 31 de julio de 1941. AMAE, R1080/25.

${ }^{71}$ «Intrucciones al embajador en Río de Janeiro», Ministerio de Asuntos Exteriores. 31 de julio de 1941. AMAE, R1080/25.

72 "Carta del Canciller del Consejo de la Hispanidad al presidente del mismo, ministro de Asuntos Esteriores", 17 de julio de 1941. AMAE, R1080/25.

${ }_{73}$ «Informe reservado del embajador de España en Río de Janeiro al ministro de Asuntos Exteriores", 26 de julio de 1941. AMAE, R1080/25. 
actividades del Consejo. A fines de agosto de 1941 se constataba la existencia de numerosos focos de tensión en Hispanoamérica, cuyas manifestaciones más importantes fueron las decisiones de los Gobiernos de Argentina y Chile sobre ayuda mutua en la defensa de la neutralidad de toda la costa, y negativa a ceder bases en el Estrecho de Magallanes a Estados Unidos ${ }^{74}$.

Otras actuaciones sugeridas por el Consejo dentro del marco de neutralización de la influencia norteamericana, eran el fomento de la solidaridad militar con los diversos países hispanoamericanos, para lo que sugería «invitar cada año a dos o tres naciones hispanoamericanas a enviar un representante a los cursos de la Escuela Superior de Guerra» ${ }^{75}, y$ «reforzar nuestro frente diplomático en América», elevando a la categoría de Embajadas algunas de nuestras Legaciones ${ }^{76}$.

El nombramiento de Gómez Jordana, su insistencia en la postura española de neutralidad y el acercamiento a los aliados, supusieron un cambio de actitud que se ponía de manífiesto en la denegación de la solicitud del Jefe Nacional de SEU para el envío de la revista Haz a través de las embajadas en Hispanoamérica ${ }^{77}$.

Era también tarea del Consejo de la Hispanidad la gestión de Congresus, constando su intervención en varios. En noviembre de 1941 se celebró en Chile el Congreso Eucarístico. La Cancilleria del Consejo informó favorablemente la solicitud de participación, incluso la posible ostentación por parte de un Cardenal español de la representación papal ${ }^{78}$. El informe de la Cancillería no pareció tener gran eficacia, pues con fecha posterior se redactaba otro insistiendo en la «beneficiosa repercusión que para los fines de la Hispanidad ha de tener la presencia de un Prelado

74 «Carta del Canciller del Consejo de la Hispanidad al Presidente del mismo, ministro de Asuntos Exteriores", 27 de agosto de 1941. AMAE, R1080/25.

75 «Carta del Canciller del Consejo de la Hispanidad al Presidente del mismo, ministro de Asuntos Exteriores", 30 de julio de 1941. AMAE, R1080/25.

${ }_{76}$ «Carta del Canciller del Consejo de la Hispanidad al Presidente del mismo, ministro de Asuntos Exteriores", 30 de octubre de 1941. AMAE, R1080/25.

7 «Informe del Gabinete Diplomático del Ministerio de Asuntos Exteriores al ministro sobre la posible difusión de la revista Haz a través de las embajadas", 21 de julio de 1943. AMAE, R1080/13.

${ }_{78}$ «Informe del Canciller del Consejo de la Hispanidad al Presidente del mismo, ministro de Asuntos Exteriores, sobre la representación española en el Congreso Eucarístico de Chile», 18 de septiembre de 1941. AMAE, R1080/25. 
español en nombre del Papa» ${ }^{79}$. Estos dos informes eran contestados desde el Ministerio de Asuntos Exteriores, explicando las causas del abandono de la cuestión. Los posibles candidatos eran el Cardenal Segura, figura «combatidísima por los rojos» y el Cardenal Vidal y Barraquer, «para quien el sector separatista catalán guarda estimación y consideraciones». Ambas personalidades podían plantear situaciones desagradables, y en evitación de la polémica que se podría suscitar se prefería renunciar al honor de la representación papal ${ }^{80}$.

En junio de 1941 el Arzobispo de Salta (Argentina) se dirigía al embajador de España solicitándole su asistencia a un «Congreso de la Hispanidad", que se celebraría en esa ciudad al año siguiente. En octubre el Arzobispo se volvía a poner en contacto con el embajador para darle cuenta de sus gestiones, en las que éste no había colaborado para evitar los recelos que su actuación pudiera plantear. El Arzobispo se había mostrado de acuerdo con estas consideraciones y con el mantenimiento de España alejada de la organización ${ }^{81}$. Pese a ello, el Canciller del Consejo de la Hispanidad, apenas tuvo noticias del tema, se dirigió al Arzobispo «apoyando la idea, felicitándole por ella y ofreciendo la colaboración del Consejo para los efectos a que hubiese lugar» ${ }^{82}$. El Arzobispo agradeció profundamente los ofrecimientos del Canciller, pero insistía en mantener en esta iniciativa un "carácter exclusivamente americano». En la misma carta hablaba de una posible postergación de la fecha ${ }^{83}$. Efectivamente, en octubre de 1942 lo único que se celebró fue el solemne acto inaugural, con la asistencia del Presidente de la República Argentina y su ministro de Asuntos Exteriores ${ }^{84}$. Este acto fue considerado por el embajador de España como un éxito desde el punto de vista de la nación argentina, dada la asistencia de las más altas autoridades, pero como un fracaso desde la óptica diplomática, pues pese a haber sido invitados los

79 «Nuevo informe del Canciller del Consejo de la Hispanidad al Presidente del mismo, ministro de Asuntos Exteriores, sobre la representación española en el Congreso Eucarístico de Chile", 23 de septiembre de 1941. AMAE, 1080/25.

so "Informe "muy reservado" del Gabinete Diplomático del Ministerio de Asuntos Exteriores al Canciller del Consejo de la Hispanidad sobre la posible representación española en el Congreso Eucaristico de Chile", 25 de septiembre de 1941. AMAE, R1080/25.

${ }_{81}$ «Informe del embajador de España en Argentina al ministro de Asuntos Exteriores», 4 de diciembre de 1941. AMAE, R1730/70.

82 «Informe del Canciller del Consejo de la Hispanidad al subsecretario del Ministerio de Asuntos Exteriores", 15 de enero de 1942. AMAE, R1730/70.

${ }_{83}$ «Carta del Arzobispo de Salta al Canciller del Consejo de la Hispanidad», 2 de enero de 1942. AMAE, R1730/70.

84 «Programa de temas del Primer Congreso de la Cultura Hispanoamericana a realjzarse en Buenos Aires en octubre de 1943", AMAE, R1730/70. 
representantes en Buenos Aires de Hispanoamérica, Portugal y Estados Unidos, a última hora excusaron su asistencia. Según el embajador, «las órdenes de Washington fueron aceptadas con verdadera sumisión" ${ }^{85}$. El resto de las sesiones del Congreso se pensaban celebrar el año siguiente ${ }^{86}$, pero en abril de 1943, a pregunta del ministro de Asuntos Exteriores español sobre el tema, se recibía la siguiente contestación: «no es posible pensar en nada semejante mientras no termine la guerra y exista entre la Argentina y las demás Repúblicas americanas la falta de unanimidad que hoy las separa” ${ }^{87}$.

El Consejo de la Hispanidad, desde su Sección Cultural, llevó a cabo otras actividades de menor relevancia, como fueron invitaciones a intelectuales hispanoamericanos ${ }^{88}$, organización de exposiciones, normalmente coincidentes con la celebración de actos conmemorativos ${ }^{89}$, concesión de becas a estudiantes hispanoamericanos ${ }^{90}$, dotación de premios a la idea de la Hispanidad ${ }^{91}$, y un largo etcétera de actividades en el campo de la cultura.

La documentación que se ha encontrado relativa a las actividades de la Sección Jurídica y la Sección Política del Consejo ha sido muy escasa. De la primera el documento más representativo es el Resumen de Actividades del año 1945, donde se ponía de manifiesto que las funciones de dicha Sección se centraban en la realización de informes de rutina y en la elaboración de estudios para la difusión en Hispanoamérica de la normativa legal española ${ }^{92}$. Sólo se ha encontrado constancia do-

${ }^{85}$ «Despacho del embajador en Argentina al ministro de Asuntos Exteriores», 22 de septiembre de 1942. AMAE, R1730/70.

${ }^{86}$ «Despacho urgente del Subsecretario de Asuntos Exteriores al Canciller del Consejo de la Hispanidad", 23 de julio de 1942. AMAE, R1730/70.

${ }^{87}$ "Telegrama del embajador de España en Argentina al ministro de Asuntos Exteriores", 20 de abril de 1943. AMAE, R1730/70.

${ }_{88}$ "Carta del subsecretario de Asuntos Exteriores al cónsul General de España en Buenos Aires", 17 de marzo de 1943. AMAE, R2603/25; "Carta del subsecretario de Asuntos Exteriores al cónsul General de España en Montevideo", 17 de marzo de 1943. AMAE, R2603/25.

${ }_{89}$ «Inauguración de la exposición "Monumenta Cartographica Indiana" en el Ministerio de Asuntos Exteriores", 12 de octubre de 1942. AMAE, R1081/17; "Inauguración de la Exposición Nacional del Libro del Mar, enmarcada en los actos de conmemoración de la llegada de Cristóbal Colón a Barcelona», abril de 1943. AMAE, R1080/10.

90 «Factura a cuenta del Consejo de la Hispanidad», 27 de agosto de 1943. AMAE, $\mathrm{R} 4052 / 5$.

${ }^{91}$ «Telegrama de la Legación de España en Costa Rica al ministro de Asuntos Exteriores», 10 de marzo de 1942. AMAE, R2603/25.

${ }_{92}$ "Resumen de actividades del año 1945. Sección Jurídica», AMAE, R1910/26. 
cumental de una actuación jurídica relacionada con el mundo hispanoamericano. Consistia en una consulta del Ministro de Ecuador en Vichy a la Sección Jurídica del Consejo sobre el conflicto de límites entre Ecuador y Perú. La razón de esta consulta residió en la pertenencia a dicho organismo de Ramón Menéndez Pidal, autor de una memoria sobre el tema en 1908, a petición del rey Alfonso XIII ${ }^{93}$.

La Sección Política estaba dividida para su funcionamiento en dos Negociados, el de Información y el Religioso ${ }^{94}$. El Negociado de Información elaboraba, periódicamente, informes sobre la situación en América, expuestos en sesiones convocadas a tal fin. Aunque hay constancia de su existencia, ninguno de estos informes aparece en la documentación manejada ${ }^{95}$.

El Negociado religioso intentó, inicialmente, desarrollar una importante actividad de centralización de información. Para ello solicitó de todas las representaciones españolas en Hispanoamérica la recogida de datos sobre la organización eclesiástica y las publicaciones periódicas de carácter religioso en dichos países ${ }^{96}$. Este ímpetu inicial pareció chocar con un cierto desinterés por parte de los representantes españoles, lo que llevó al Negociado a elevar una queja al ministro ${ }^{97}$. La situación no pareció remediarse, y el otro documento relativo a las actividades del Negociado religioso que se ha manejado deja constancia de que su actividad se vio reducida a la redacción mensual de un panorama católico, utilizado como material de propaganda. En el mismo documento se ponía de manifiesto que «la Sección Social y la Económica, que figuraban en el Reglamento, no han tenido jamás vida administrativa, aunque de la última existiese un Jefe, sin personal de él dependiente, que a voluntad propia cesó en el año objeto de esta Memoria» ${ }^{94}$.

Ha quedado de manifiesto, a lo largo de lo anteriormente expuesto, que el Consejo de la Hispanidad conoció su época de relieve durante el

\footnotetext{
93 «Carta de Ximénez de Sandoval a Menéndez Pidal», 29 de septiembre de 1941. AMAE, R1080/25.

${ }_{94}$ «Resumen de actividades del año 1945. Sección política», AMAE, R1910/26.

95 «Invitación para la reunión de la Sección Política del Consejo de la Hispanidad donde se dará a conocer el informe elaborado por dicha Sección sobre la situación actual de los países americanos", 29 de enero de 1942. AMAE, R1080/25.

${ }_{96}$ «Carta del ministro de Asuntos Exteriores a las representaciones españolas en Hispanoamérica y Filipinas", noviembre de 1941. AMAE, R1080/25.

${ }_{97}$ «Escrito de la Subsección Religiosa al Canciller del Consejo de la Hispanidad», febrero de 1942. AMAE, R1080/25.
} 
ministerio de Serrano Súñer, para, a raíz de la salida de éste del Gobierno, ir cayendo en el anonimato y viéndose relegado a tareas culturales. Este proceso no fue, por tanto, puntual, sino que duró casi tres años, hasta el final de la contienda mundial. En diciembre de 1945 se procedió a la reorganización general del Ministerio de Asuntos Exteriores, modificación que se llevó a cabo «al final de la guerra, para evitar que las modificaciones hechas en el curso de ella le dieran carácter circunstancial». En esta ley quedó asignada al Instituto de Cultura Hispánica la finalidad de «mantener los vínculos espirituales entre todos los pueblos que componen la comunidad cultural de la Hispanidad». Las disposiciones transitorias autorizaban al ministro para organizar por decreto el Instituto de Cultura Hispánica, quedando derogada la ley fundacional del Consejo de la Hispanidad. Asimismo, el presupuesto y personal administrativo del Consejo pasaban a formar parte del Instituto de Cultura Hispánica ${ }^{98}$.

Los Gobiernos de las repúblicas hispanoamericanas iban a mantener, oficialmente, una política de ambigüedad con respecto a las tesis de Hispanidad. Esta política se traducía en una aceptación del funcionamiento de un organismo, creado en un país con el que se tenían relaciones, pero, a la vez, en un desinterés y una falta de colaboración en su desarrollo, del que se temía una intromisión política y una vuelta a viejas formas imperialistas. Pero, al mismo tiempo que los Gobiernos mantenían esa postura, en la prensa hispanoamericana se iba a librar una auténtica batalla sobre las intenciones de España al crear el Consejo de la Hispanidad.

En Chile se registraba un ambiente desfavorable con cada nuevo paso que se daba hacia el normal funcionamiento del Consejo de la Hispanidad, ya que la prensa se obstinaba en verlo como un instrumento al servicio de una "determinada política» ${ }^{99}$. En el diario El Mercurio se consideraba que la creación del organismo era una idea feliz, pero se observaba que para que tuviera éxito era preciso que estuviera rodeado de garantías de imparcialidad, que fuera ajeno a consideraciones de orden político o a «ideas de penetración ideológica». También había que descartar cualquier tentación directora que intentara colocar a los países de Hispanoamérica en condición de subordinación con respecto a

${ }^{98}$ Ley de 31 de diciembre de 1945.

99 «Informe del embajador de España en Chile al ministro de Asuntos Exteriores», 21 de enero de 1941. AMAE, R1652/62. 
España ${ }^{100}$. Otros diarios chilenos resultaban más críticos. Así El Siglo consideraba el Consejo de la Hispanidad como «la quinta columna de Franco para los países de Hispanoamérica" ${ }^{101}$, y en Defensa se propagaba la noticia de que el objetivo del Consejo era «difundir en América las doctrinas totalitarias» ${ }^{102}$.

El talante de dichos editoriales hizo que al embajador de España no le quedara más remedio que remitir una nota a todos los periódicos donde afirmaba que el Consejo no estaba adscrito a ninguna misión política, ni nacional ni internacional, y que pretendía lograr sus fines sin subordinación ni mediatización de los pueblos de habla hispana ${ }^{103}$.

A la hora de estudiar la postura de la prensa argentina, se ha encontrado la traducción de un informe de la embajada alemana en Argentina sobre la repercusión que tuvo en la república sudamericana tanto la creación del Consejo de la Hispanidad como la idea de Hispanidad en la que se basaba ${ }^{104}$. Consideraba la citada embajada que el Consejo había merecido la mayor atención por parte de la prensa argentina, que veía con agrado la acentuación de los lazos espirituales con España, pero se rechazaba la idea de una tutela española, pues los países sudamericanos se sentían, por lo menos, tan progresistas como España en la civilización. El interés de la embajada alemana en la extensión de la idea de Hispanidad no parecía muy limpio. Efectivamente, en el último párrafo del informe se reconocía la necesidad de adoctrinar a los colaboradores que enviaba el consejo de la Hispanidad a Hispanoamérica, siendo de gran utilidad política su contacto previo con la embajada alemana en Madrid. Este escrito parecía confirmar las tesis mantenidas por distintos medios de comunicación hispanoamericanos sobre la función propagandística asignada al Consejo.

El Gobierno ecuatoriano apoyaba la idea de Hispanidad que no implicara infiltración política en América, sino que tendiera a asegurar los

100 «El Consejo de la Hispanidad», El Mercurio, Chile, 10 de enero de 1941. AMAE, R1652/62.

${ }_{101}$ El Siglo, Chile, 9 de enero de 1941. AMAE, R1652/62.

102 "El Consejo de la Hispanidad", Defensa, Chile, 13 de enero de 1941. AMAE, $\mathrm{R} 1652 / 62$.

103 “Informe del embajador de España en Chile al ministro de Asuntos Exteriores», 25 de enero de 1941. AMAE, R1652/62.

104 «Traducción de un informe de la Embajada alemana en Buenos Aires. AMAE, R1652/62. 
derechos que en Europa tenían las naciones hispánicas ${ }^{105}$. En Colombia, en el diario El Tiempo, propiedad del Presidente de la República, se atacaba duramente al Consejo de la Hispanidad ${ }^{106}$, y se acusaba a España de que, siguiendo órdenes "de fuera», y con propósitos de dominación, atosigaba a las naciones de América con la idea de la Hispanidad ${ }^{107}$. Más favorable parecía la postura del Presidente de la República del Perú, que con motivo de las fiestas a celebrar en el IV Centenario de la muerte de Pizarro afirmaba que uhará todo lo posible para que ... resulten brillantísimas y sirvan para estrechar vínculos con la Madre Patria» ${ }^{108}$. Las opiniones en la prensa peruana no resultaban tan comedidas. En Crónica se atacaba duramente la idea de Hispanidad, a la que calificaba de campaña de Falange, de carácter antidemocrático y antiamericano ${ }^{109}$, y en El Comercio se escribía "América ama a España, pero no está dispuesta a secundar la política totalitaria de Franco» ${ }^{110}$.

En Centroamérica, la creación del Consejo de la Hispanidad se recibió de forma diversa. En la República de Guatemala, el Presidente se declaraba admirador del ideal de Hispanidad que preconizaba el régimen de Franco ${ }^{111}$. Sin embargo, en el resto de las repúblicas centroamericanas el ambiente era hostil. Tanto en Costa Rica como en Nicaragua el Consejo de la Hispanidad sonaba a «algo nefasto y traidor, y sus partidarios son considerados, como el propio Consejo, instrumento de Hitler» ${ }^{112}$. Algo similar ocurría en la República de El Salvador, donde se registraba una "atmósfera antiespañola» "113, y en la República de Honduras, cuya prensa atacaba el régimen franquista de forma "verdaderamente vergonzosa», ataque que era un reflejo de la actitud guber-

105 «Nota del embajador de Ecuador en Brasil al embajador de España en Brasil», 14 de noviembre de 1941. AMAE, R1652/62.

106 «Resúmenes para el Sr. subsecretario», Legación en Bogotá, 17 de noviembre de 1944. AMAE, R1652/68.

107 "La Hispanidad revenida", El Tiempo, Colombia, 25 de junio de 1941. AMAE, R1080/25.

108 «Nota del embajador de España en Lima al Canciller del Consejo de la Hispanidad», 5 de agosto de 1941. AMAE, R1080/25.

109 «El peligro de la propaganda falangista ante la Conferencia de Cancilleres", Crónica, Perú, 19 de diciembre de 1941. AMAE, R1652/68.

${ }_{110}$ "Gualda y oro", El Comercio, Perú, 23 de agosto de 1942. AMAE, R1652/68.

111 «Radiograma de la Secretaría de Relaciones Exteriores de la República de Guatemala a Su Excelencia el Generalismo", 15 de mayo de 1941. AMAE, R1652/62.

112 «Informe de la Legación de España en Costa Rica», 30 de noviembre de 1941. AMAE, R1652/62.

113 «Informe de la Legación de España en San Salvador», 18 de septiembre de 1941. AMAE, R1652/68. 
namental, que obligaba a los españoles establecidos en aquella República a pedir la nacionalidad hondureña, pues en caso contrario "serían perseguidos y arruinados" ${ }^{114}$.

Por último, en Méjico la situación resultaba mucho más clara, pues el Gobierno no disimulaba su rechazo al régimen español. Sin embargo, la colonia española, insistió en mantener una postura de discreción "para evitar que cualquier apariencia diera fundamento a quienes la calumnian" ${ }^{115}$. Esta postura iba a favorecer el apoyo del Gobierno mejicano a dicha colonia, y así, ante la noticia de que España pudiera entrar en guerra al lado de las potencias del Eje, aseguraba al comercio e industria españoles que no sufrirían ninguna sanción en sus capitales ${ }^{116}$.

114 «Informe de la Legación de España en San Salvador», 15 de enero de 1942. AMAE, R1652/68.

115 "Resúmenes para el Sr. subsecretario", Legación de España en Guatemala, 28 de febrero de 1942. AMAE, R1652/68.

116 «Resúmenes para el Sr. subsecretario», Embajada de España en Washington, 4 de enero de 1942. AMAE, R1652/68. 